\title{
Effect of randomly distributed polypropylene fiber reinforcement on the shear behavior of sandy soil
}

https://doi.org/10.2478/sgem-2019-0014

received February 6, 2019; accepted May 27, 2019.

Abstract: The inclusions of geosynthetic materials (fibers, geomembranes and geotextiles) is a new improvement technique that ensures uniformity in the soil during construction. The use of tension resisting discreet inclusions like polypropylene fibers has attracted a significant amount of attention these past years in the improvement of soil performance in a costefficient manner. A series of direct shear box tests were conducted on unreinforced and reinforced Chlef sand with different contents of fibers (0, $0.25,0.5$ and0.75\%) in order to study the mechanical behavior of sand reinforced with polypropylene fibers. Samples were prepared at three different relative densities 30\%, 50\% and $80 \%$ representing loose, medium dense and dense states,respectively, and performed at normal stresses of 50, 100 and $200 \mathrm{kPa}$. The experimental results show that the mechanical characteristics are improved with the addition of polypropylene fibers. The inclusion of randomly distributed fibers has a significant effect on the shear strength and dilation of sandy soil. The increase in strength is a function of fiber content, where it has been shown that the mechanical characteristics improve with the increase in fiber content up to $0.75 \%$, this improvement is more significant at a higher normal stress and relative density.

Keywords: Sand; direct shear box tests; polypropylene fibers; shear strength; normal stress; relative density.

\footnotetext{
*Corresponding author: Noureddine Della, Universite Hassiba Benbouali de Chlef, Chlef, Algeria, E-mail: n.della@univ-chlef.dz Mehdi Missoum Benziane: PhD. preparation, Laboratory of Materials Science and Environment (LMSE), Hassiba Benbouali University of Chlef, Algéria. Laboratory of Geomaterials, Hassiba Benbouali University of Chlef, Algéria

Sidali Denine: PhD., Laboratory of Materials Science and Environment (LMSE), Hassiba Benbouali University of Chlef, Algéria Sedat Sert: Dr, Faculty of Engineering, Department of Civil Engineering, Geotechnical Laboratory, Sakarya University, Turkey Said Nouri: Dr, Laboratory of Structures, Geotechnics and Risks, Hassiba Benbouali University of Chlef, Algeria
}

\section{Introduction}

Several works have been carried out in the laboratory on soil samples to study the influence of the addition of reinforcement under several types and forms on the behavior of the soil. ${ }^{[14,15,21,22,24,30,36]}$ Reinforcing soils using tension resisting elements is an attractive means of improving the performance of soil in a cost effective manner. The use of random discrete flexible fibers mimics the behavior of plants roots of surface vegetation and contribute to the stability of soil mass by adding strength to the near-surface soils in which the effective stress is low. [40,19,20] Laboratory and some in situ pilot test results have led to encouraging conclusions concerning the potential use of flexible fibers for the reinforcement of fine granular materials providing an artificial replication of the effects of vegetation. ${ }^{[3,29,12,35,37,42,32]}$

Numerous experiments carried out on fiber-reinforced sandy soil have shown that the shear strength of sand increases when the discrete fibers are added to the soil. ${ }^{[2,11,12,15,18,27,28,39]}$ G. RanjanG., Vasan R.M. and Charan H.D. (1994) also found thatfiber content increases the strength of fiber-reinforced soil at peak and limits the reduction of residual shear strength. ${ }^{[33]}$ Furthermore, Yetimoglu T. and Salbas O.A. (2003) reported that the inclusion of fibers into sand pose great potential to reduce the brittleness of soils and improve its ductility in order to limit loss of post peak strength. ${ }^{[41]}$ Fiber-reinforced specimens are able to maintain the shear stress with continuing deformation even at large strains, suggesting that these materials are very ductile. Also, Romero R.J. (2003) and Liu J. et al. (2011) have shown that reinforcement inclusions reduce the potential for the occurrence of liquefaction and convert a strain softening response into a strain hardening response. ${ }^{[34,26]}$

Fiber reinforced soil behaves as a composite material in which fibers of relatively high tensile strength are embedded in a matrix of soil. The randomly distributed fibers capture and redistribute loads through their tensile strength, mobilizing a wider mass of soil, which in turn greatly improve the mechanical response of the material. ${ }^{[1,17,23]}$ Experimental results from various tests 

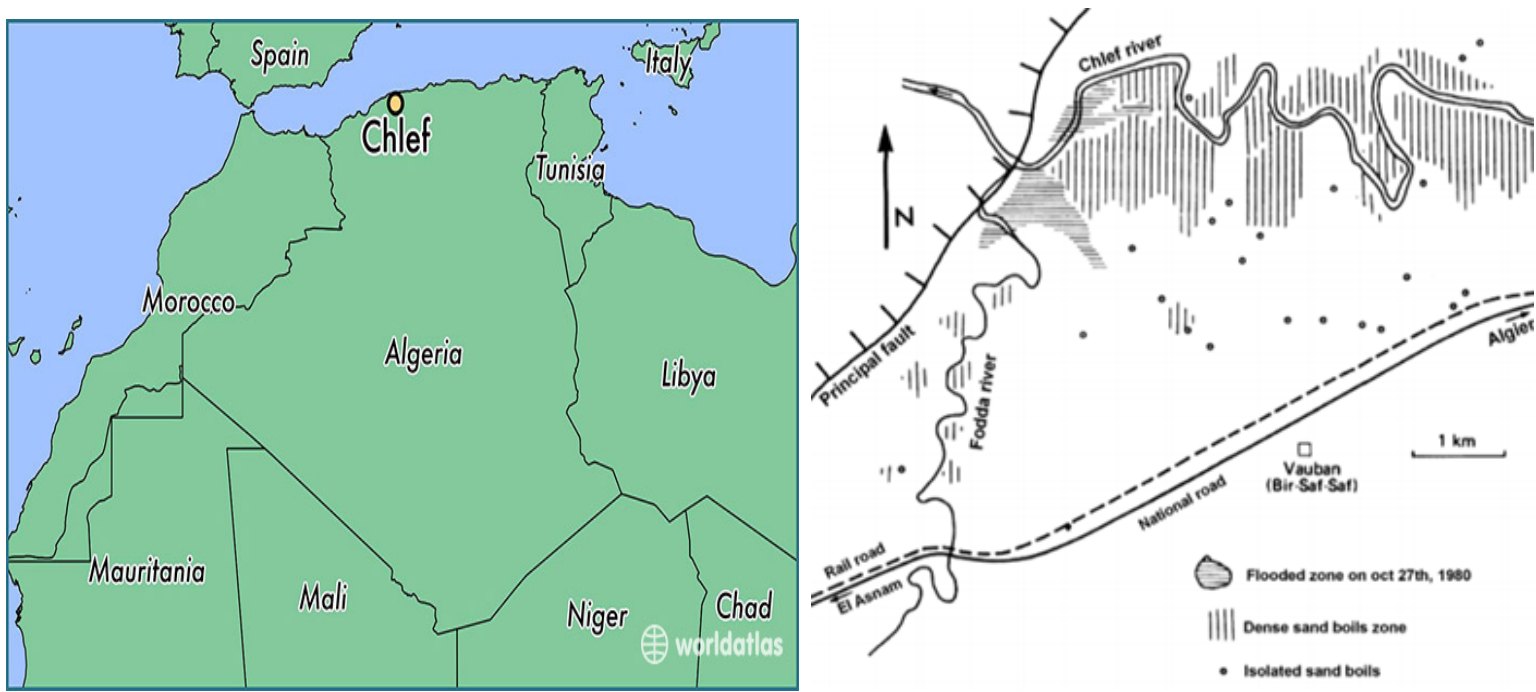

Figure 1: Localization of the liquefaction phenomenon in the Chlef valley during the earthquake of October 1980 ${ }^{[16]}$

(direct shear, unconfined compression and triaxial compression) have confirmed that the efficiency of fiber treatment is highly dependent on the fiber concentration, on testing conditions (e.g., stress and strain levels, stress path and loading direction) and on a large number of variables related equally to the physical and dimensional characteristics of both fiber and sand matrix (e.g.,fiber and particle sizes and particle size distribution, particle shape and fiber surface, fiber/grain frictional properties, stiffness) as well as their spatial configuration (e.g., matrix packing and fiber orientation, fiber distribution). However,a limited number of studies have been focused on the investigation of the behavior of polypropylene fiber reinforced sand using the direct shear apparatus. This paper presents the experimental results of direct shear tests carried out on sand samples reinforced with polypropylene fibers. Results of this study are presented and discussed regarding the effect of relative density, normal stress and fiber percentage on the shearbehavior of reinforced soil.

\section{Materials and laboratory procedures}

The experimental program is a series of direct shear box test performed on Chlef sandy soil obtained from the Chlef river banks (Algeria), unreinforced and reinforced samples with polypropylene-fibers (fiber content of 0.25 , 0.5 and 0.75 by mass), three different densities and under a normal stress of 50, 100, $200 \mathrm{kPa}$.

\subsection{Materials}

\subsubsection{Soil}

The soil used in the present study was a sand collected from the Chlef river banks in the north of Chlef Algeria. According to Durville J.L. and Meneroud J.P. (1983), this region has experienced the appearance of soil liquefaction during the last earthquake of October 1980. ${ }^{[16]}$ The phenomenon appeared on a vast alluvial valley traversed by OuedChlef and at the confluence zone with OuedFodda (Figure 1). Numerous testswere carried out on the Chlef sand. ${ }^{[4,9,10,13,25]}$ The soil used is classified as poorly graded sand (SP). Figure 2 presents the grain size distribution curve of the sand..$^{[5]}$ The engineering properties of Chlef sand are given in Table 1. The tests were conducted on sand samples prepared at different initial relative densities of 30,50 and $80 \%$ representing respectively loose, medium dense and dense states of deposition and subjected to three normal stresses of 50 , 100 and $200 \mathrm{kPa}$.

\subsubsection{Fiber reinforcement}

The fiber used in this study was a white monofilament polypropylene fiber with an average length of $12 \mathrm{~mm}$ and a diameter of $32 \mu \mathrm{m}$ (Figure 3). Different fiber contents, Fc $=0 \%, 0.25 \%, 0.5 \%$ and $0.75 \%$ were used. A series of direct sheartests was conducted to investigate the parameters that affect the shear strength behavior of fiber-reinforced sand.Physical and mechanical properties offiber are 


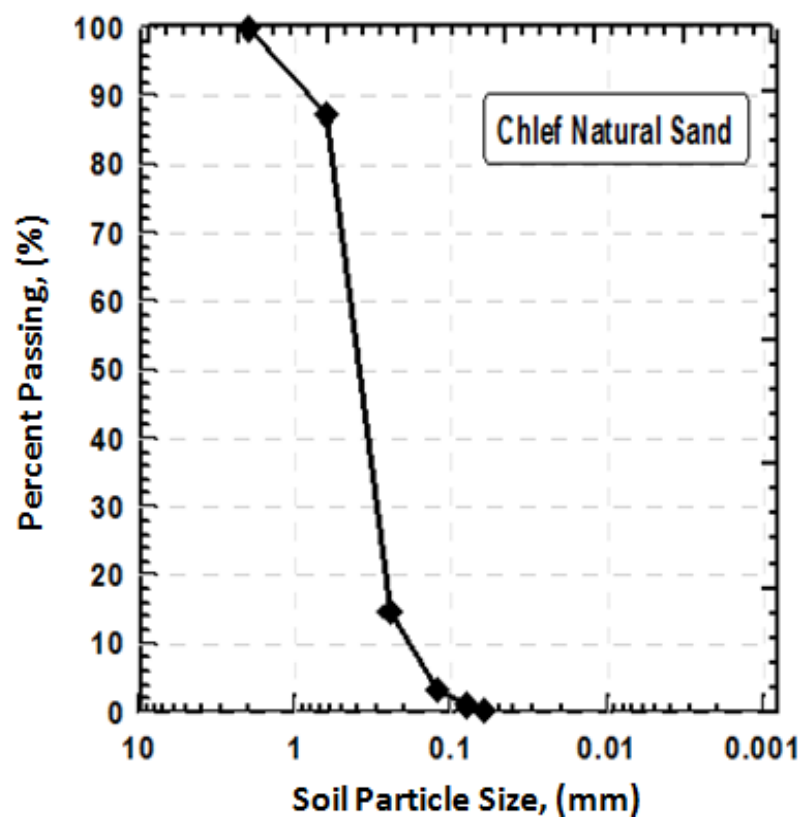

Figure 2: Grain size distribution curve of the Chlef sand.

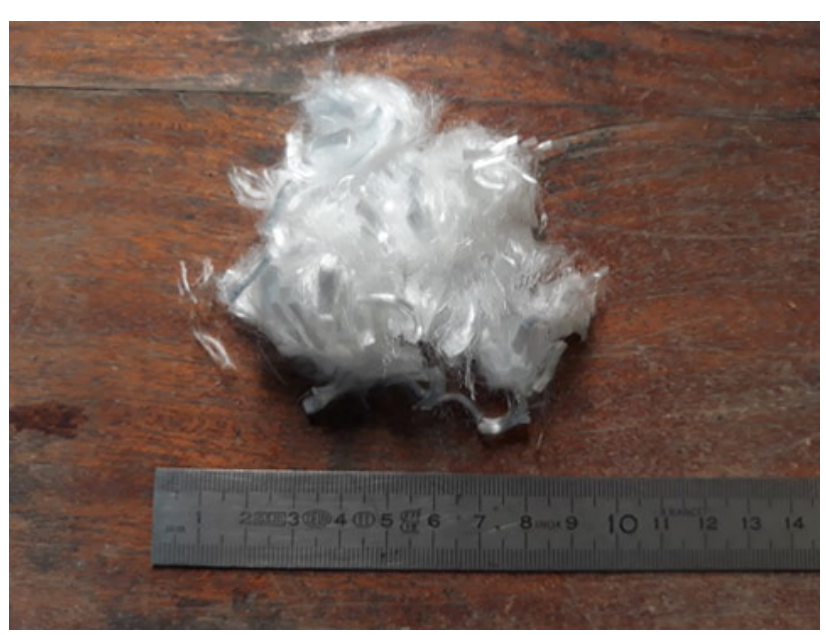

Figure 3: Monofilament polypropylenefiber.

shown in Table 2 (supplied by the manufacturing company 'Polyfibres').

\subsection{Test procedures}

Laboratory reconstituted samples of unreinforced and reinforced sand with polypropylene fiber were used in this study. Sample preparation was first conducted by determining the required mass of sand and fiber for mixture. The concentration of fibers $(\mathrm{Fc})$ included in a composite is defined as percentage of dry mass of sand:
Table 1: Engineering properties of Chlef sand.

\begin{tabular}{lll}
\hline Sand Properties & $\begin{array}{l}\text { Standard test } \\
\text { specifications }\end{array}$ & Value \\
\hline Medium grain size, $\mathrm{D}_{50}(\mathrm{~mm})$ & ASTM D-422 & 0.40 \\
Maximum diameter, $\mathrm{D}_{\max }(\mathrm{mm})$ & ASTM D-422 & 2.00 \\
Coefficient of uniformity, $\mathrm{C}_{\mathrm{u}}()$. & ASTM D-422 & 2.227 \\
Coefficient of curvature, $\mathrm{C}_{\mathrm{c}}()$. & ASTM D-422 & 0.891 \\
Mean specific gravity, Gs(.) & ASTM D854-02 & 2.665 \\
Maximum void ratio, $\mathrm{e}_{\max }()$. & ASTM D4253-00 & 0.85 \\
Minimum void ratio, $\mathrm{e}_{\min }()$. & ASTM D4254-00 & 0.56 \\
\hline
\end{tabular}

Table 2: Physical and mechanical properties of polypropylene fiber.

\begin{tabular}{lllll}
\hline $\begin{array}{l}\text { Specific } \\
\text { gravity }\end{array}$ & $\begin{array}{l}\text { Length } \\
(\mathrm{mm})\end{array}$ & $\begin{array}{l}\text { Diameter } \\
(\mu \mathrm{m})\end{array}$ & $\begin{array}{l}\text { Tensile strength } \\
(\mathrm{MPa})\end{array}$ & $\begin{array}{l}\text { Young modulus } \\
(\mathrm{GPa})\end{array}$ \\
\hline 0.91 & 12 & 32 & $600-700$ & $3.0-3.5$ \\
\hline
\end{tabular}

$$
F c(\%)=100 \times \frac{W_{f}}{W_{s}}
$$

Where $\mathrm{W}_{\mathrm{f}}$ and $\mathrm{W}_{\mathrm{s}}$ are the mass of fibers and the mass of dry sand, respectively. The specimens were manually prepared by adding and mixing the oven dried sand with fibers as shown in Figure 4.A special attention during sample preparation was given to ensure a similar level of mixing for all the samples tested. In view of carrying out each test, the following procedure was adopted.The calculated soil mass was divided into three equal parts; the fiber mass was also divided accordingly. Each soil mass was manually mixed with its opposing fiber mass in order to obtain three equal mixtures. Visual examination of the prepared specimens proved the mixtures to be satisfactorily uniform. The obtained mixtures were then disposed in layers in the mold with a defined compacting process proper to each density. Each test was repeated to ensure the reliability of the results.

36 direct shear box tests were conducted in this study on unreinforced and reinforced sand with different fiber contents (0, $0.25,0.5$ and $0.75 \%$ by mass) using the preparation method of dry pluviation.The reinforced and unreinforced samples were both in a loose $(\mathrm{Dr}=30 \%)$, medium dense $(50 \%)$ and dense $(\mathrm{Dr}=80 \%)$ state. All of the parameters considered in testing programme are listed in Table 3.

All the tests were conducted at the Laboratory of Materials Science and Environment (LMSE) at University 


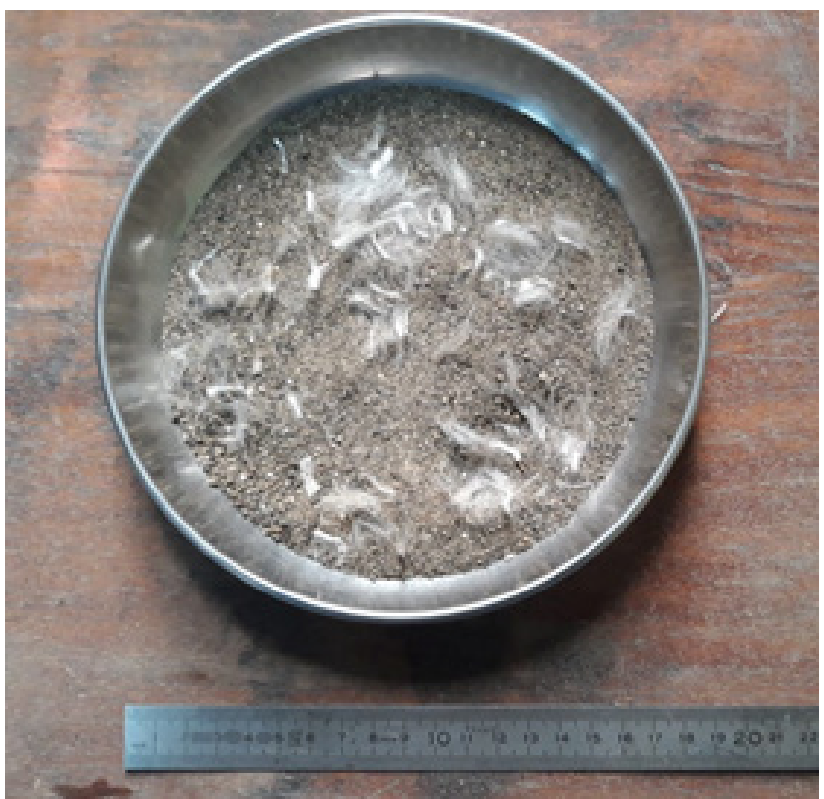

Figure 4: Sample preparation.

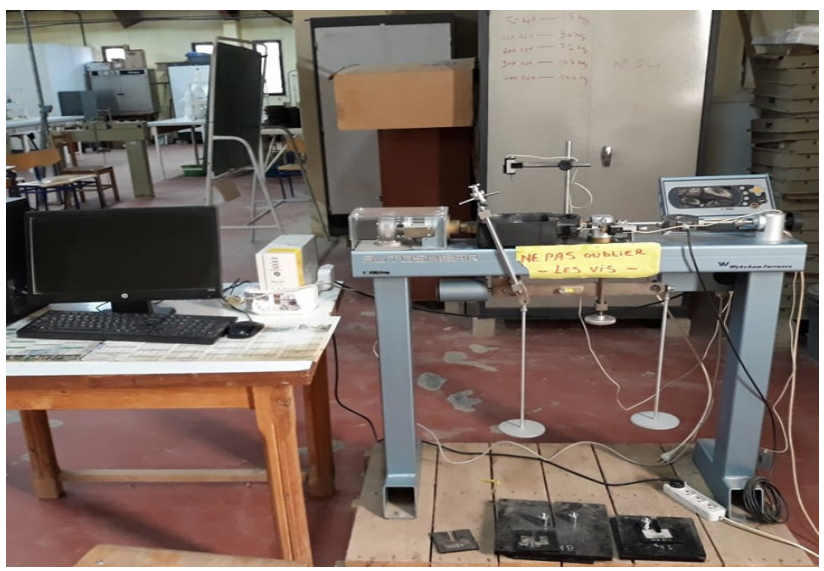

Figure 5: View of the direct shear box apparatus.

Hassiba Benbouali of Chlef in Algeria. Fiber reinforcement tests were conducted using a standard laboratory Shear strength apparatus with a box specimen of $60 \times 60 \mathrm{~mm}$ in the plan. The thickness of all samples was $25 \mathrm{~mm}$. Figure 5 presents a general view of the setup showing direct shear box apparatus and the data acquisition system.

\section{Results and discussion}

\subsection{Effect of fiber content}

Several studies on the fiber effect content on the shear behavior of soils have proved that soil mechanical
Table 3: Experimental program.

\begin{tabular}{lll}
\hline $\begin{array}{l}\text { Relative } \\
\text { density, } \operatorname{Dr}(\%)\end{array}$ & Fiber content, $\mathrm{Fc}(\%)$ & Normal stress, $\mathrm{6}_{\mathrm{n}}(\mathrm{kPa})$ \\
\hline 30 & $0,0.25,0.5$ and 0.75 & 50,100 and 200 \\
50 & $0,0.25,0.5$ and 0.75 & 50,100 and 200 \\
80 & $0,0.25,0.5$ and 0.75 & 50,100 and 200 \\
\hline
\end{tabular}

characteristics increase with the increase in fiber content. Hence, this investigation studies the effect of fiber content on the shear behavior of Chlef sand. In the graphs below, test results are presented and compared regarding the effect of fiber content $(0.25,0.5$ and $0.75 \%$ by mass), normal stress and relative density.

\subsubsection{Loose samples $(\mathrm{Dr}=30 \%)$}

Figure $6 \mathrm{a}$ presents shear strength versus horizontal displacement. Results show an important increase in the shear strength for all the percentages of fiber reinforcement studied. However, fiber content of $0.75 \%$ by mass was proven to be the most effective, where the peak shear strength reached takes a value of $151 \mathrm{kPa}$ for the reinforced samples and $99 \mathrm{kPa}$ for the unreinforced samples. The effect of reinforcement on the volumetric behavior showed that adding fiber reinforcements increases the contractive tendency of loose sand and significantly for higher fiber contents (Figure 6b); this is due to the contribution of fiber on the improvement of the soil confining stress thanks to the tension developed in the fibers. This kind of behavior was also observed by Romero R.J. (2003). ${ }^{[34]}$ Moreover, from Figure 6c, it can be noted that the fiber content has a significant effect on the strength parameters (the cohesion and the friction angle). The friction angle has been established where the slope takes the values of 0.59 and 0.68 for fibers' content equal to 0.25 and $0.5 \%$ respectively, and a maximal value of 0.69 for a fiber content of $0.75 \%$.

\subsubsection{Medium dense samples $(\mathrm{Dr}=50 \%)$}

The effect of polypropylene fibers on the shear strength development and the volumetric deformation for a medium relative density $(\mathrm{Dr}=50 \%)$ will be established. Figures $7 \mathrm{a}$ and $7 \mathrm{~b}$ show that the increase in the shear strength is proportional to the increase in fiber content. This is due to the increase in the contact area between fibers and soil particles that leads to increased friction at 

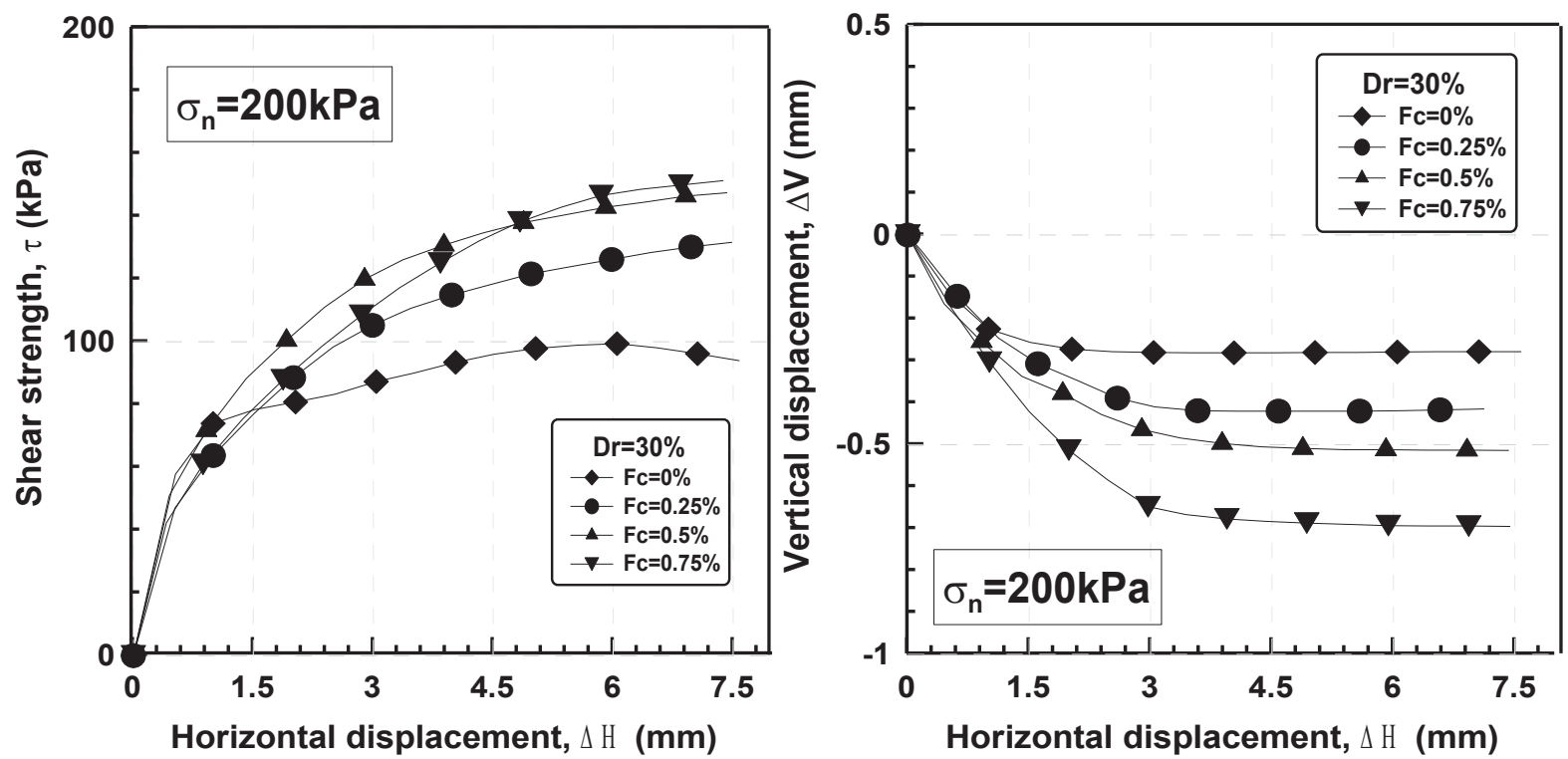

(a) (b)

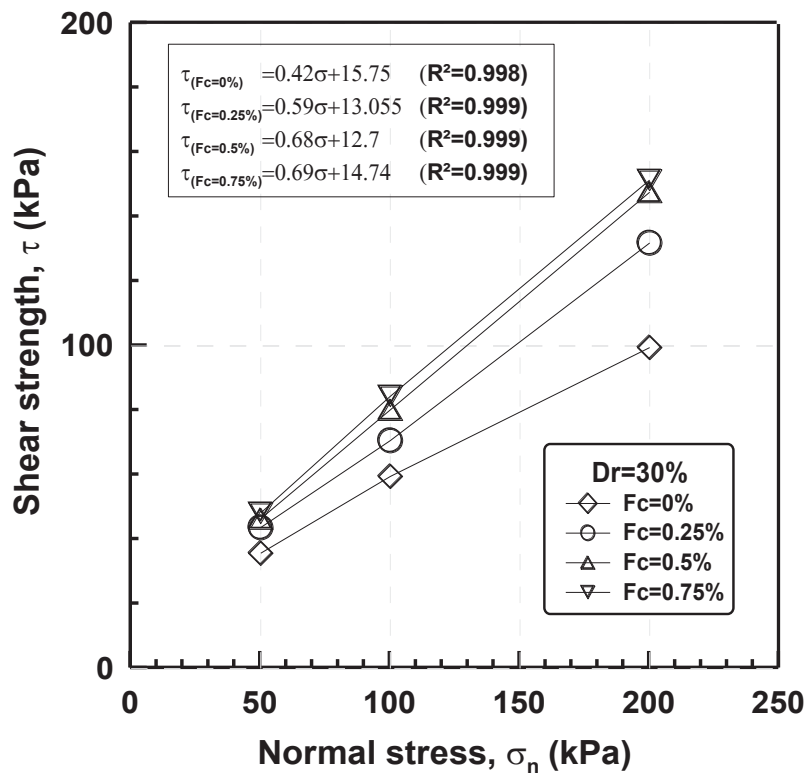

(c)

Figure 6. Effect of fiber content on shear behavior, normal stress of $200 \mathrm{kPa}$ and a relative density $\mathrm{Dr}=30 \%$ : (a)variation of the shear strength versus horizontal displacement,(b)variation of vertical displacement versus horizontal displacement, (c)intrinsic curves

the interface. At the same time, fibers can generate many crossover points and create fiber networks that reinforce the spatial confinement effect in the soil. As a result, the strength of the mixture increases to the maximum. ${ }^{[38]}$ It is noticeable that the addition of fiber has greatly improved the strength of the sand, as it reached the peak strength of $165 \mathrm{kPafor}$ a fiber content of 0.75\%.Besides, displacement curves of unreinforced and reinforced medium sand specimens have almost shown contractive behavior (Figure $7 \mathrm{~b}$ ). Where, it has been observed that the introduction of fiber inclusions limits the soil dilatancy. Also, it has been shown in the intrinsic curves (Figure 7c) that all reinforced specimens have higher shear strength than of the unreinforced sand. The values of the slope of 

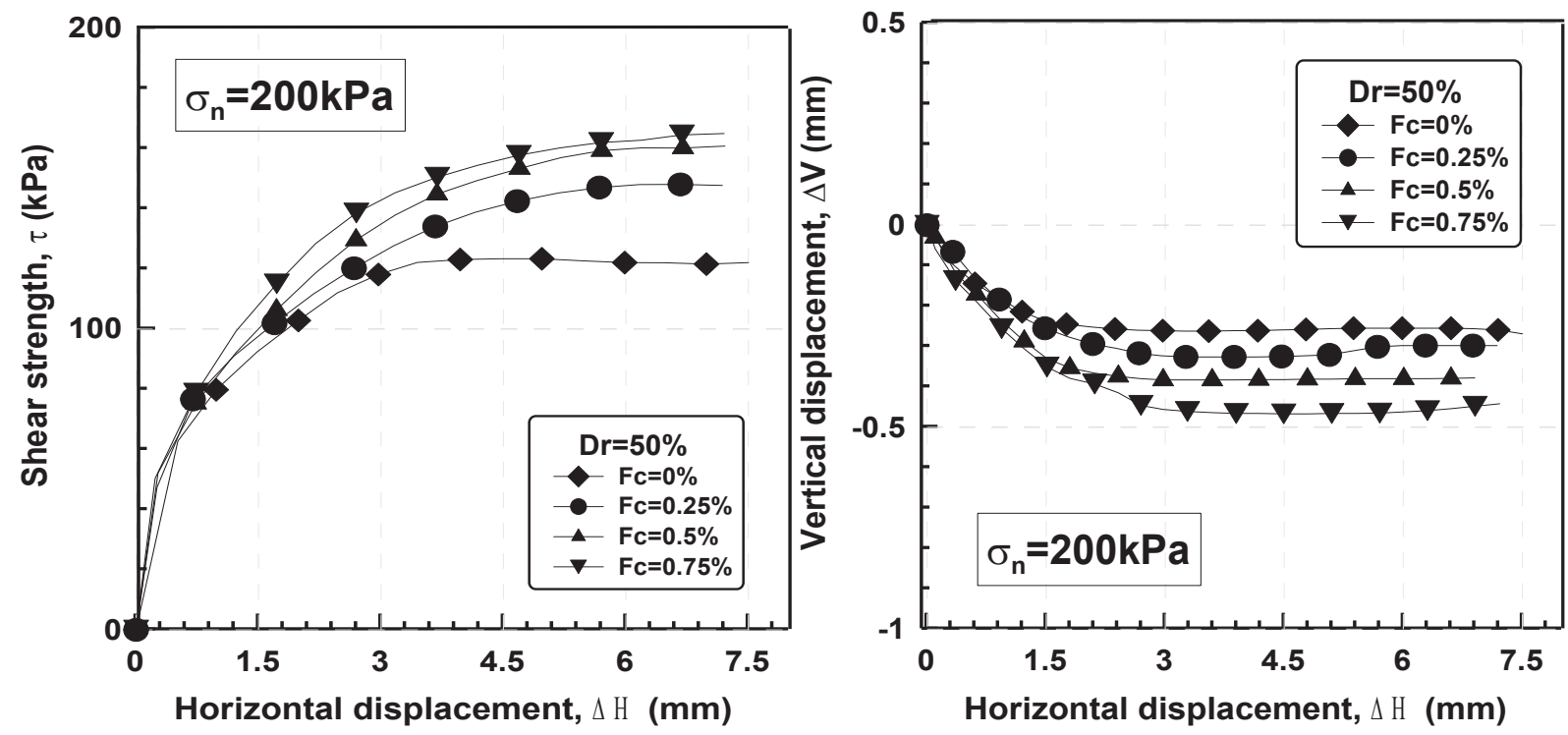

(a) (b)

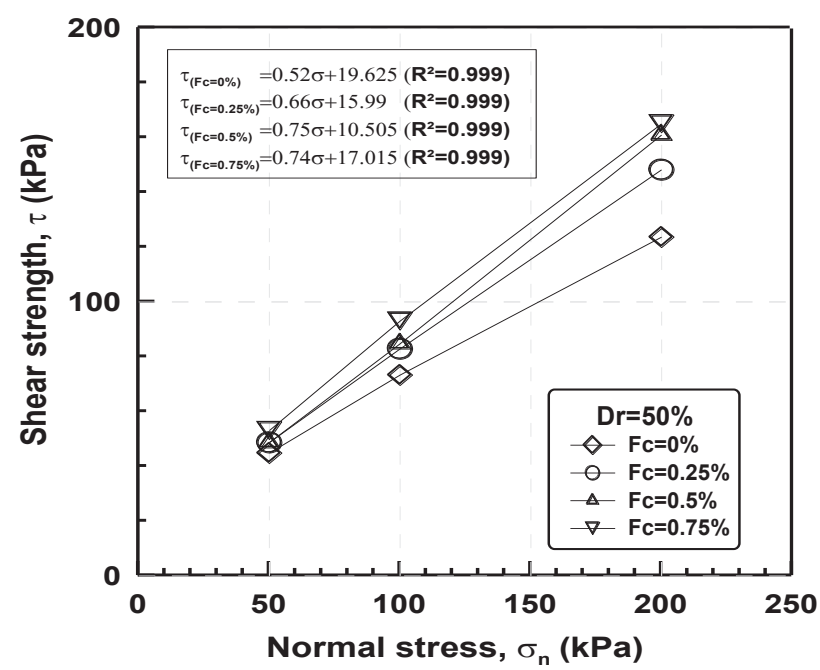

(c)

Figure 7.Effect of fibercontent on shear behavior, normal stress of $200 \mathrm{kPa}$ and a relative density $\mathrm{Dr}=50 \%$ : (a)variation of the shear strength versus horizontal displacement,(b)variation of vertical displacement versus horizontal displacement, (c)intrinsic curves

the friction angle for fiber contents of $0.25 \%, 0.5 \%$ and $0.75 \%$ were $0.66,0.75,074$, respectively.

\subsubsection{Dense samples $(\mathrm{Dr}=\mathbf{8 0} \%)$}

Figure $8 \mathrm{a}, 8 \mathrm{~b}$ and $8 \mathrm{c}$ present the curves of shear behavior for a sample prepared at high relative density $(\mathrm{Dr}=80 \%)$ and subjected to a normal stress of $200 \mathrm{kPa}$ for different fiber contents varying from 0.25 to $0.75 \%$. Figures $8 \mathrm{a}$ and $8 \mathrm{~b}$ show the shear strength versus the horizontal displacement and the horizontal displacement versus the vertical displacement respectively; the same observation can be done regarding the case of loose and average dense states. Results show that the shear strength increases linearly with the increase in fiber content, where the maximum shear strength has been shown for a fiber content of $0.75 \%$, the peak shear strength recorded for the reinforced sample is $194 \mathrm{kPa}$ comparing with $164 \mathrm{kPa}$ for the unreinforced samples.The same observations can be made regarding the effect of fiber inclusion on the vertical deformation of the samples. The reinforced samples 

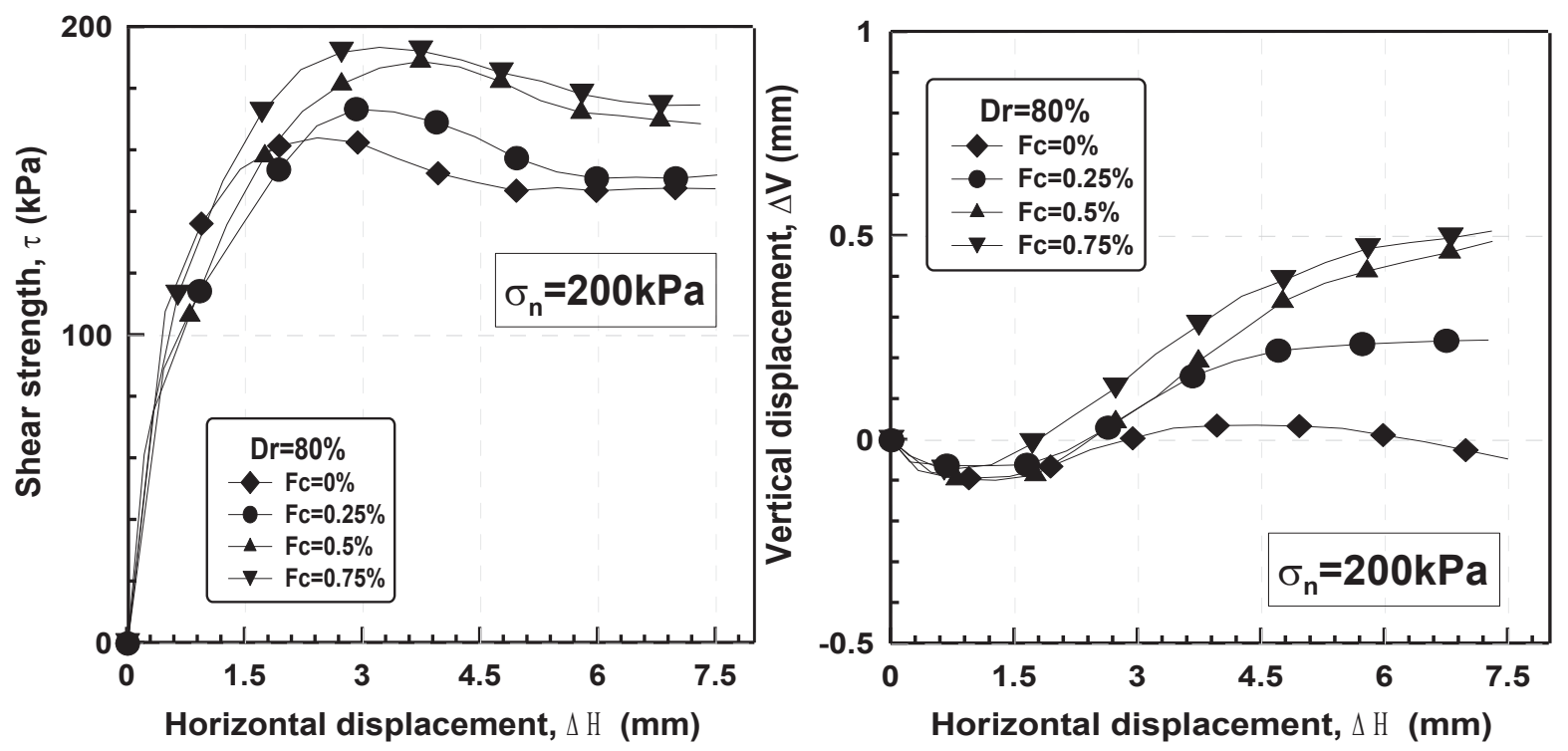

(a) (b)

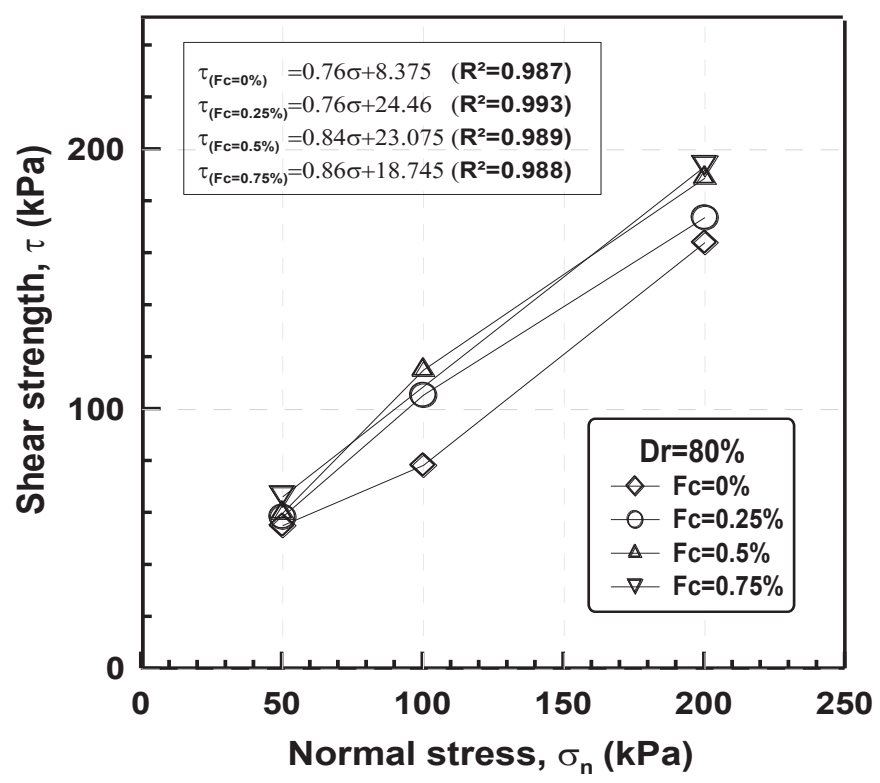

(c)

Figure 8. Effect of fibercontent on shear behavior, normal stress of $200 \mathrm{kPa}$ and a relative density $\mathrm{Dr}=80 \%$ : (a)variation of the shear strength versus horizontal displacement,(b)variation of vertical displacement versus horizontal displacement, (c)intrinsic curves

demonstrated an increase in the vertical displacement with the increase of fibers' content. Hence, it is observed that dense samples have initially shown contractive behavior followed by appeared dilation tendency especially by adding more amounts of fibers (Figure 8b). Results indicate that the reinforced dense samples have shown more dilation than the unreinforced one. In addition, the increase in the cohesion c value (Figure 8c) was significant at each fibers' content studied, where it showed a maximum augmentation from a value of 8.375 $\mathrm{kPa}$ for an unreinforced sample to a value of $18.745 \mathrm{kPa}$ for a reinforced sample with a fiber content of $0.75 \%$. Figure $8 \mathrm{c}$ shows the effect of fibers' content on the slope of the friction angle, where a value of 0.86 for a fiber reinforced content of $0.75 \%$ can be compared with a value of 0.76 for the unreinforced sample, which suggests that the friction 


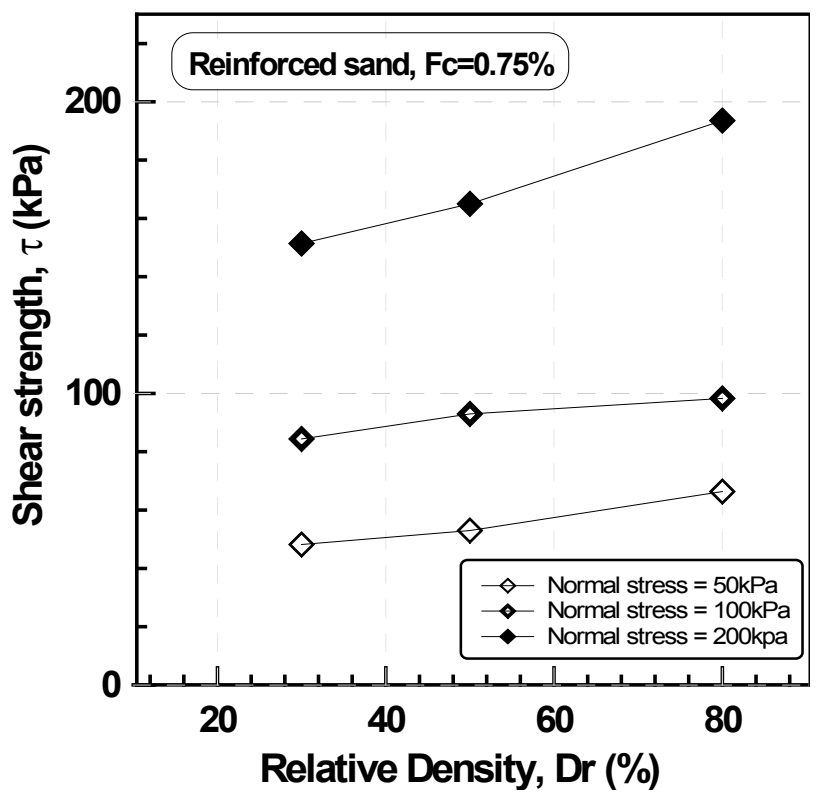

Figure 9: Effect of relative density and normal stress on the shear strength of fiber reinforced sand with a fiber content $\mathrm{Fc}=0.75 \%$.

angle is significantly affected by fiber content. This result is in good agreement with that of Khebizi et al.(2018). ${ }^{[39]}$

\subsection{Effect of relative density and normal stress}

Figure 9 presents the effect of relative density on the behavior of fiber reinforced sand; it can be seenfrom this figure that the shear stress of dense samples is greater than the medium dense and loose samples. Liu J. etal. (2011) ${ }^{[26]}$ established that an increase in sand density results in a more effective inter-facial contact area between the fiber-sand matrix.In addition, samples with a higher density will result in a greater contact and locking force between adjacent sand particles and a greater plastic deformation and surface roughness of fibers. Meanwhile, the lock effect increases with the fiber content. Thus, the maximum shear strength of the samples increases with the fiber content.The normal stress has a similar effect to the relative density on the shear stressfor every fiber content studied.The increase in shear strength is more important for a normal stress of $200 \mathrm{kPa}$ than $50 \mathrm{kPa}$.Therefore, it can be noted that the normal stress has a significant effect on the improvement in shear strength of fiber reinforced sand. Similar observations were made by Prabakar J. and Sridhar R.S. (2002). ${ }^{[31]}$

\section{Conclusion}

A series of direct shear tests were conducted to study the effect of polypropylene fiber inclusions on the mechanical characteristics of Chlef sand. Based on the results obtained from this study, the following conclusions can be made:

1. The efficiency of fiber inclusions is highly dependent on the fiber concentration, since the shear strength of the reinforced specimens increased relatively with the increase in fiber content.

2. Test results show that the maximum values of cohesion and friction angle increases with the increase of fibers, which means that the mechanical characteristics of fiber reinforced soil are significantly affected by the fiber content for all relative densities studied.

3. The inclusion of fiber reinforcement decreases the dilatancy of the soil for samples prepared at loose density. However, adding fibers enhances the dilation tendency of dense samples. This is due to the fiber sand matrix, which is highly dependent on relative density and the contribution of fiber reinforcement, respectively.

4. Relative density has a significant impact on the shear strength of fiber reinforced soils as an increase in sand density results in a more effective inter-facial contact area between the fiber-sand matrix.A similar effect was found in the case ofnormal stress on the improvement of the shear strength of fiber-reinforced sand. Therefore, a special consideration must be given to sand density and normal stressin practical applications.

\section{References}

[1] Abtahi, M.,, Ebadi, F., Hejazi, M., Sheikhzadeh, M. (2008). On the use of textile fibers to achieve mechanical soil stabilization. In: 4th Inttex cloth des conf, Dubrovnik, Croatia; 5-8 October.

[2] Ahmad, F., Mujah, D., Hazarika, H., and Safari, A. (2012). Assessing the potential reuse of recycled glass fibre in problematic soil applications, Journal of Cleaner Production, 35, 102-107.

[3] Al Refeai, O. (1991). Behaviour of granular soils reinforced with discrete randomly oriented inclusions. GeotextGeomembr,10, 319-33.

[4] Arab, A., Shahrour, I., Lancelot, L. (2011). Alaboratory study of liquefaction of partially saturated sand. J. Iber. Geol. 37(1), 29-36.

[5] ASTM D 422-63. Standard test methods for particle-size analysis of soils. West Conshohoken, PA: ASTM International. 
[6] ASTM D 4253-00. Standard test methods for maximum index density and unit weight of soils using a vibratory table. West Conshohocken, PA: ASTM International.

[7] ASTM D4254-00. Standard test methods for minimum index density and unit weight of soils and calculation of relative density. West Conshohoken, PA: ASTM International.

[8] ASTM D854-02. Standard test methods for Specific Gravity of Soil Solids by Water Pycnometer. West Conshohocken, PA: ASTM International.

[9] Belkhatir, M., Missoum, H., Arab, A., Della, N. and Schanz, T. (2011). The undrained shear strength characteristics of silty sand: an experimental study of the effect of fines. Geologia Croatica, 64(1), 31-39.

[10] Belkhatir, M., Schanz T., Arab, A. (2013). Effect of fines content and void ratio on the saturated hydraulic conductivity and undrained shear strength of sand-silt mixtures, Environ. Earth Sci., 70(6), 2469-2479. doi.org/10.1007/s12665-013-2289-z

[11] Benessalah,I., Arab, A., Villard, P., Sadek, M., Kadri, A. (2015). Laboratory study on shear strength behaviour of reinforced sandy soil: effect of glass-fibers content and other parameters. Arab J SciEng 41(4), 1343-1353.

[12] Consoli C, Festugato L, Heineck S. (2009). Strain-hardening behaviour of fiber reinforced sand in view of filament geometry. Geosynth Int, 16, 109-15.

[13] Della, N., Arab, A., Belkhatir, M. (2011). A laboratory study of the initial structure and the overconsolidation effects on the undrained monotonic behavior of sandy soil from Chlef region in northern Algeria. Arab. J. Geosci. 4(5-6), 983-991.

[14] Denine, S., Della, N., Dlawar, M. R., Sadok, F., Canou, J., Dupla, J.-C. (2016). Effect of geotextile reinforcement on shear strength of sandy soil: laboratory study. Stud Geotech et Mech, 38 (4), 3-13.

[15] Diambra, A., Ibraim, E., Wood, D.M., Russell, A.R. (2010). Fibre reinforced sands: experiments and modelling. Geotextiles and Geomembranes, 28(3), 238- 250.

[16] Durville, J.L., Meneroud, J.P. (1982). Phenomenes geomorphologiques induits par le seisme d'El-Asnam, Algerie. Bull. Liaison Labo. P. et Ch., 120, juillet-aout, , 13-23.

[17] Ghiassian, H., Jamshidi, R., Tabarsa. A. (2008). Dynamic performance of Toyoura sand reinforced with randomly distributed carpet waste strips. In: 4th Dec geol earth eng and soil dyn conf, Sacramento, California, USA, May, 18-22.

[18] Gray, D.H., Ohashi, H., (1983). Mechanics of fiber reinforcement in sands. Journal of Geotechnical Engineering, ASCE 109(3), 335-353.

[19] Greenwood, J., Norris, E., Wint, J. (2004). Assessing the contribution of vegetation to slope stability. Geotech Eng, Proc the ICE, GE4, 199-207.

[20] Greenwood J. SLIP4EX (2006). a program for routine slope stability analysis to include the effects of vegetation, reinforcement and hydrological changes. GeotechGeolEng,24, 449-65.

[21] Haeri, S.M., Noorzad, R., Oskoorouchi, A.M., (2000. Effect of geotextile reinforcement on the mechanical behavior of sand, Geotextiles and Geomembranes, 18(6), 385-402.

[22] Ibraim, E., Diambra, A., Muir Wood, D., Russell, A.R. (2010). Static liquefaction of fibre reinforced sand under monotonic Loading. Geotextiles and Geomembranes, 28 (4), 374-385.

[23] Jamshidi, R., Towhata, I., Ghiassian, H., Tabarsa, R. (2010). Experimental evaluation of dynamic deformation characteristics of sheet pile retaining walls with fiber reinforced backfill. Soil Dyn Earthq Eng, 30, 438-46.

[24] Kim, Y.S., Oh, S.W., Cho, D.S. (2010) Effect of non-woven geotextile reinforcement on mechanical behavior of sand, J. Korean Geosynthetics Society, 9(4), 39-45.

[25] Krim, A., Zitouni, Z., Arab, A., Belkhatir, M. (2013) Identification of the behavior of sandy soil to static liquefaction and microtomography. Arab. J. Geosci. 6(7), 2211-2224.

[26] Liu, J., Wang, G., Kamai, T., Zhang, F, Yang, J., Shi, B. (2011). Static liquefaction behaviour of saturated fiber-reinforced sand in undrained ring-shear tests, Geotextile and Geomembranes, 29(5), 462-471.

[27] Maher, M.H., Gray, D.H. (1990). Static response of sand reinforced with fibres. Journal of Geotechnical Engineering, ASCE 116 (11), 1661-1677.

[28] Micha1owski, R.L., Cermak, J. (2002). Strength anisotropy of fiber-reinforced sand. Computers and Geotechnics 29(4), 279-299.

[29] Michalowiski L, Zhao A. (1996). Failure of fiber-reinforced granular soils. J Geotech Eng ASCE, 122(3), 226-34.

[30] Nouri, S., Nechnech, A., Lamri, B., Lurdes Lopes, M. (2015). Triaxial test of drained test reinforced with plastic layers, Arab. J.Geosci., 9(1), 1-9.

[31] Prabakar, J., Sridhar, R.S. (2002). Effect of random inclusion of sisal fibre on strength behaviour of soil, Construction and Building Materials, 16(2), 123-131.

[32] Park, T., Ann Tan, S., (2005). Enhanced performance of reinforced soil walls by the inclusion of short fiber, Geotexiles and Geomembranes 23(4), 348-361.

[33] Ranjan, G., Vasan, R.M., and Charan, H.D. (1994). Behaviour of plastic fiber reinforced sand. Geotextiles and Geomembranes, 13(8), 555-565.

[34] Romero, R.J. (2003). Development of a constitutive model for fiber-reinforced soils. Dissertation submitted in partial fulfillment for the requirements of the Doctoral Degree, University of Missouri-Columbia.

[35] Santoni L, Tingle S, Webster L. (2001). Engineering properties of sand-fiber mixtures for road construction, J. Geotech. Geoenviron. Eng., 127(3), 258-68.

[36] Denine, S., Della N., Feia S., Muhammed, R.D., Canou, J., Dupla, J.-C. (2018). Shear behavior of geotextile-reinforced Chlef sand in the Mediterranean region: Laboratory investigation, Marine Georesources\&Geotechnology, accepted, published online.

[37] Tingle, S., Santoni, S., Webster, L., (2002). Full-scale field tests of discrete fiber-reinforced sand, J. Trans. Eng. ASCE;128(1): 9-16.

[38] Wei, L., Chai, S.X., Zhang, H.Y., Qian Shi, Q. (2018). Mechanical properties of soil reinforced with both lime and four kinds of fiber, Construction and Building Materials, 172, 300308.

[39] Khebizi, W., Della, N., Denine, S., Canou? J., Dupla, J-C. (2018). Undrained behaviour of polypropylene fibre reinforced sandy soil under monotonic loading, Geomechanics and Geoengineering, 14(1), 3040.

[40] Wu, T., McOmber, M., Erb, T., Beal, E. (1988). Study of soil-root interaction. J GeotechEng ASCE; 114 (12):1351-1375.

[41] Yetimoglu, T., Salbas, O.A. (2003). Study on shear strength of sands reinforced with randomly distributed discrete fibers, Geotextiles and Geomembranes, 21 (2), 103-110.

[42] Zornberg, G. (2002). Discrete framework for limit equilibrium analysis of fiber reinforced soil. Géotechnique, 52(8), 593-604 